Original Research Article

\title{
Pre-treatment effect of myo-inositol and 1-5, methyltetrahydrofolate in ovulation induction oocyte quality and pregnancy outcome in clomiphene resistance polycystic ovarian disease
}

\author{
Ankit Bhardwaj $^{1 *}$, Anand Shukla ${ }^{1}$, Sunita Singh', Rajni Agarwal ${ }^{2}$
}

\begin{abstract}
${ }^{1}$ Department of Pharmacology,
${ }^{2}$ Department of Obstretics and Gynaecology, SIMS, Hapur, Uttar Pradesh, India
\end{abstract}

Received: 01 January 2018 Accepted: 29 January 2018

\section{*Correspondence to: \\ Dr. Ankit Bhardwaj, Email: drankitbhardwaj25@ gmail.com}

Copyright: (C) the author(s), publisher and licensee Medip Academy. This is an openaccess article distributed under the terms of the Creative Commons Attribution NonCommercial License, which permits unrestricted noncommercial use, distribution, and reproduction in any medium, provided the original work is properly cited.

\begin{abstract}
Background: This study was designed to assess the treatment effect of myoinositol and 1-5, methyltetrahydrofolate in oocyte quality, pregnancy outcome in clomiphene citrate resistance PCOS cases.

Methods: Authors conducted prospective open label, randomized, parallel group study in SIMS Hapur, U.P. Eligible patients full filling inclusion criteria were randomized into two groups having 25 patients in each group using myo-inositol $580 \mathrm{mg}$ and $1-5$, methyltetrahydrofolate $800 \mathrm{mcg}$ in treatment group and tab folic acid $400 \mathrm{mcg}$ in placebo group for 12 weeks. The follow-up visits are on weeks 4, 8 and 12 .

Results: 12 weeks later, 21 patients in treatment group restored one spontaneous menstrual cycle and 19 patients maintained the normal ovulatory activity in follow up cycle. Ovulation induction done in 18 patients with clomiphene citrate at the dose of $50 \mathrm{mg}$ during treatment out of which 10 conceive, as compared with only 9 women out of the 25 women ( 36 percent) in the placebo group ovulate $(\mathrm{P}>0.001)$ out of which 4 conceived. There was significant decrease in Sr. testosterone, DHEA and AMH level and estradiol level, while statically significant increase in Sr. SHBG and FSH level seen in treatment $\operatorname{group}(\mathrm{p}<0.001)$.

Conclusions: In the study, more number of studied patients get back to normal menstrual cyclicity, insulin-lowering activity and its intracellular role in oocyte maturation. Significant Dec seen in serum estradiol level at the day of HCG administration.
\end{abstract}

Keywords: Myo-inositol, L-5 methyltetrahydrofolate, Polycystic ovarian syndrome

\section{INTRODUCTION}

The polycystic ovary syndrome (PCOS) is the most common endocrine disorder in women worldwide. The syndrome is characterized by ovulatory dysfunction, hyperandrogenism, and polycystic ovaries (PCO). These features can lead to multiple symptoms with systemic as well as organ-specific aberrations.

Although the etiology of PCOS is not completely understood yet, PCOS is considered a multifactorial disorder with various genetic, metabolic, endocrine and environmental abnormalities. ${ }^{1}$ There is increasing evidence suggesting that PCOS affects the whole life of a woman, can begin in utero in genetically predisposed subjects, it manifests clinically at puberty, continues during the reproductive years. It can also expose patients to increased risk of cardiovascular disease, hypertension, diabetes and other metabolic complications, especially after menopause. ${ }^{2}$ During the fertile period it may cause anovulatory infertility and could be associated with increased prevalence of gestational complications, such as miscarriage, gestational diabetes and preeclampsia. ${ }^{3}$ The quality of oocytes plays a key role in the development of a 
clinical pregnancy. In humans, in fact oocytes of poor quality may be the cause of women infertility. ${ }^{4}$

It is now widely recognized that insulin resistance, manifesting above all in obese or overweight women, but often also in lean PCOS women, is one of the key to this complex disorder. It determines hyperandrogenism by acting synergically with luteinizing hormone (LH) on ovarian steroidogenic enzymes and on sex hormone binding globulin (SHBG) production by the liver.

Follicular fluid (FF) provides a very important microenvironment for the development of oocytes. FF may be regarded as a biological "window" reflecting metabolic and hormonal processes occurring in the microenvironment of the maturing oocyte before ovulation and also as a predictor of outcome parameters such as fertilization, embryo cleavage and pregnancy rates ${ }^{5}$ Mild to moderate intrafollicular hyperhomocysteinemia is associated with detrimental effects on reproductive outcome, ranging from congenital malformations and miscarriages to pregnancy induced hypertension and low birth weight. ${ }^{6-8}$ The main causes of hyperhomocysteinemia include a dysbalance between the intake of folate, cobalamin, pyridoxine and methionine, metabolic derangements and related genetic variations. ${ }^{9}$

It has been demonstrated that a preconception folic acid treatment positively affects the microenvironment of the maturing oocyte in humans, by decreasing total homocysteine concentrations in pooled follicular fluid and increasing follicle diameter. ${ }^{10}$ Another parameter taken into account in terms of oocyte quality in previous studies was the concentration of myo-inositol in FF. ${ }^{11,12}$ Myoinositol is an isoform of inositol and belongs to the vitamin B complex. Myo-inositol (MI) is widely distributed in nature. Considering all the results coming out from previous studies. ${ }^{13,14}$ It is clear that myo-inositol is a precursor of the synthesis of phosphoinosides, in particular it constitutes the phosphatidylinositol signal transduction system, known to be involved in the regulation of several cellular function, including cell proliferation. ${ }^{15}$ The presence of Myo-inositol in human body fluid, its role as precursor of the inositol phospholipids responsible for the generation of important intracellular signals essential for mammalian oocyte development and its higher concentration in FF containing oocytes of good quality suggests that the supplementation with myo-inositol in IVF techniques, could positively influence the final result of the reproduction technique. ${ }^{16-18}$

\section{METHODS}

The study was conducted as a prospective, follow up study, randomized, parallel-group study in Department of Pharmacology, Department of Obstretics and Gynaecology, Saraswathi Institute of Medical Sciences and Associated Hospitals, Hapur, Uttar Pradesh. During a period of January 2016 to June 2017.
Study was comprised of 100 married women of reproductive age group of 18-35 yrs. with proved clomiphene citrate resistance PCOS, attending outpatient clinic in Saraswathi medical college hospital from the period of January 2016 to June 2017 diagnosed on the base of Rotterdam criteria. 32 patients excluded out from the study due to non-fulfillment of the criteria. Of the 68 patients who entered the study 2 patients from the treatment group dropped out due to intolerance of the meden while 5 lost during the study. 9 patients lost in placebo group.

At the time of entry into the study, all the women were in the equivalent of the follicular phase of the menstrual cycle, as documented by a serum progesterone concentration below $2.5 \mathrm{ng}$ per milliliter $(8.0 \mathrm{nmol}$ per liter).

Patient was treated with, myo-inositol $1.2 \mathrm{gm}$ in two divided dose and 1-5, methyltetrahydrofolate at dose of $800 \mathrm{mcg}$ for 12 weeks and ovulation induction was done with clomiphene citrate from cycle days 2-6.

Patients was monitored by transvaginal/abdominal USG for any cyst, B/L ovarian volume and endometrium thickness on day 3 of cycle. Serum Estradiol level also measured on day 3. Follicular diameter, endometrium thickness subsequently measured on 10, 12 and 14th day of cycle. Serum estradiol level was also measured on the day of HCG injection and serum progesterone level on day 21-23 of the cycle.

HCG (5000-10000 IU i.m) was given according to the patient's body weight when at least one or more follicle measuring $18 \mathrm{~mm}$ or more will be found. Ovulation was define by transvaginal/abdominal ultrasound as the disappearance of the leading follicles, presence of follicular fluid in Douglas pouch.

In the absence of menses urine pregnancy test was done by UPT kit followed by USG abdomen after 45 days of last LMP.

The study was approved by the institutional Ethics committee. Written informed consent was obtained from all the subjects before their enrollment in the study.

\section{Inclusion criteria}

Patients with transvaginal /abdominal sonographyically diagnosed cases of PCOS with criteria of 12 or more sub capsular follicles 2-9 $\mathrm{mm}$ in diameter and/or increase in ovarian volume up to $10 \mathrm{~cm} 2$. And proved cases of clomiphene citrate resistance. All women with proved patent fallopian tubes. Normal semen analysis for their partners according to modified criteria of world health organization. 


\section{Exclusion criteria}

Patients with Hyperprolactinemia, hypercorticism and thyroid dysfunctions. Obese $>30 \mathrm{~kg} / \mathrm{m} 2$. Patients with congenital uterine anomalies, uterine myomas, intrauterine adhesions (Asher man's syndrome), endometrial polyps, chronic endometritis, Difficult to visualize/ approach any of the ovaries.

\section{Statistical analysis}

All the parameters were analyzed by using computer software SPSS 16.0 version. $\mathrm{P}$ value $<0.05$ was considered significant.

\section{RESULTS}

There was significant improvement in parameters of insulin resistance viz. fasting insulin, fasting glucose and OGTT in treatment group in comparison to placebo group. Only 3 patients recorded with fasting glucose level above $100 \mathrm{mg} / \mathrm{dl}$. While in placebo group only 2 patients showing hyperglycemia became euglycemic. Statically a significant variation seen in HOMA-IR in treatment group while placebo group show no difference in HOMA-IR.

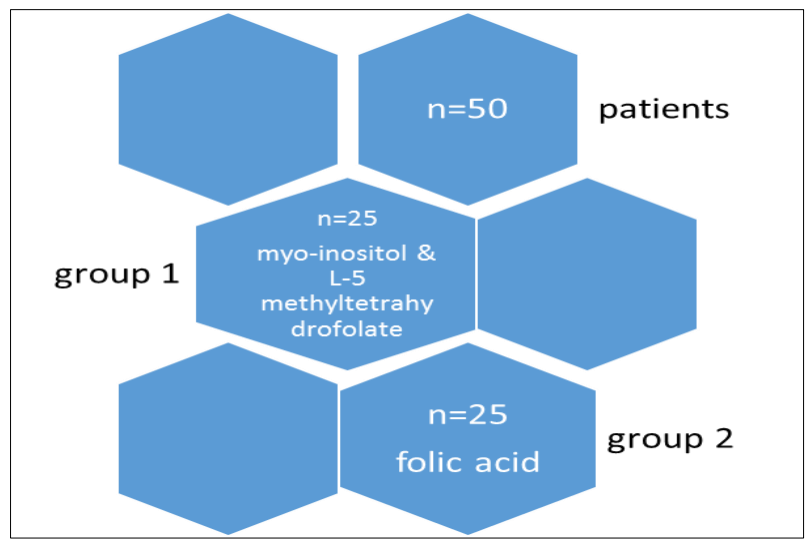

Figure 1: Randomization of the two groups.

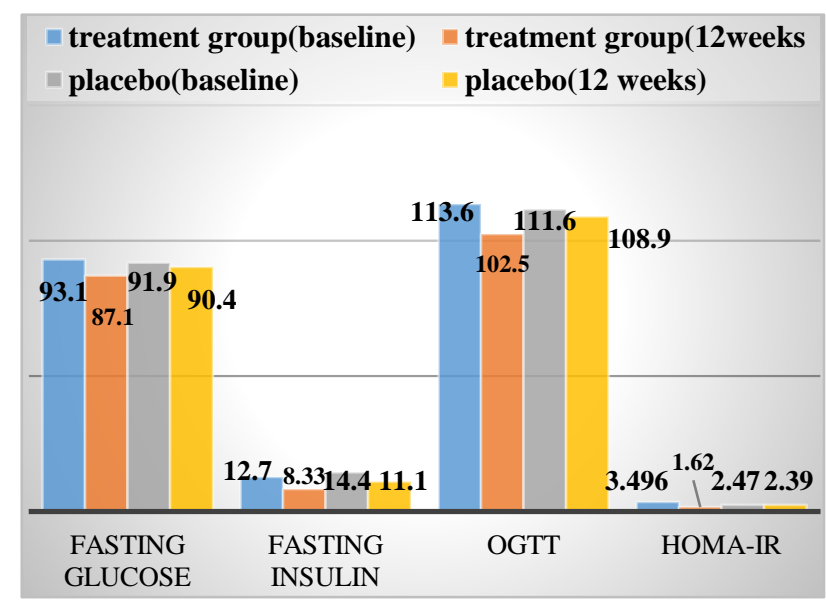

Figure 2: Mean pre and post treatment differences in bio-chemical parameters in two groups.
Table 1: Comparison of anthropometric parameters.

\begin{tabular}{|llll|}
\hline BMI (kg/m2) & $\begin{array}{l}\text { Treatment } \\
\text { group }\end{array}$ & $\begin{array}{l}\text { Placebo } \\
\text { group }\end{array}$ & $\begin{array}{l}\text { P } \\
\text { value }\end{array}$ \\
\hline $\begin{array}{l}\text { BMI kg/m2 } \\
\text { (mean } \pm \text { SD) }\end{array}$ & $25.06 \pm 3.177$ & $25.48 \pm 3.840$ & 0.6703 \\
\hline $\begin{array}{l}\text { Waist } \\
\text { circumference } \\
\text { cm } \\
\text { (mean } \pm \text { SD) }\end{array}$ & $74.66 \pm 8.57$ & $79.46 \pm 4.46$ & 0.0116 \\
\hline $\begin{array}{l}\text { Hip } \\
\text { circumference } \\
\text { (mean } \pm \text { SD) }\end{array}$ & $93.45 \pm 9.06$ & $90.76 \pm 3.60$ & 0.0561 \\
\hline $\begin{array}{l}\text { Waist hip ratio } \\
\text { (mean } \pm \text { SD) }\end{array}$ & $0.797 \pm 0.07$ & $0.876 \pm 0.0324$ & 0.0001 \\
\hline Blood pressure & mm hg (mean \pm SD) & \\
\hline Systolic BP & $121.3 \pm 10.2$ & $118.12 \pm 8.95$ & 0.2312 \\
\hline Diastolic BP & $77.8 \pm 7.44$ & $78.68 \pm 7.86$ & 0.708 \\
\hline
\end{tabular}

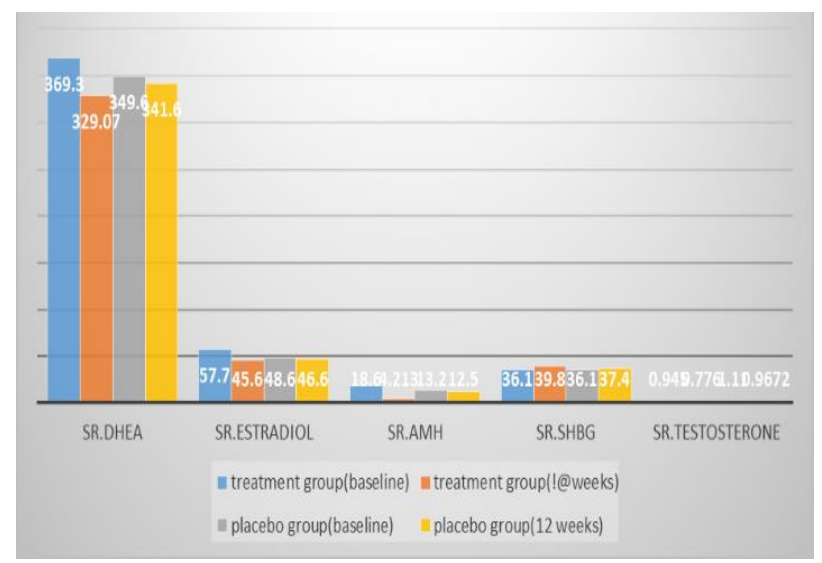

Figure 3: Pre and post treatment effect on hormonal parameters in both group.

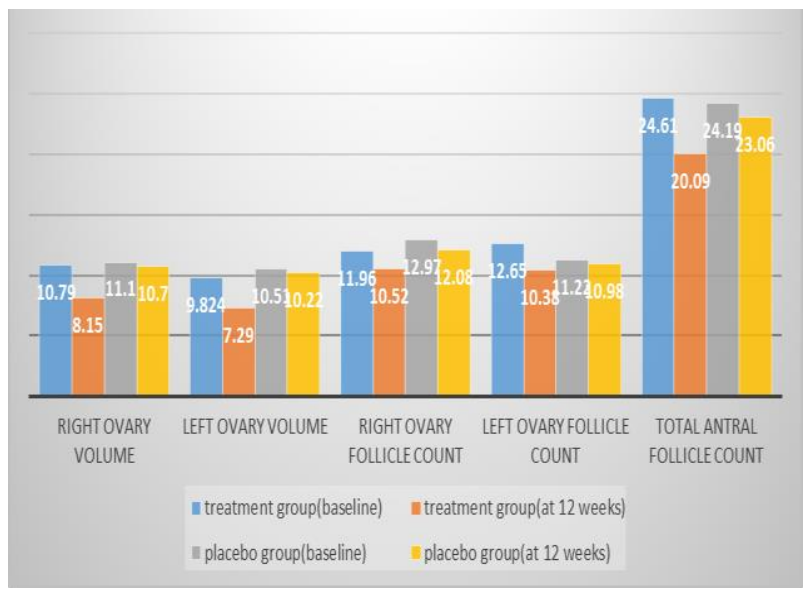

Figure 4: Comparison of mean ovary volumes and follicle counts in groups at baseline and at end of study.

Twenty two out of the twenty women in the Myo-inositol with L-5, Methyltetrahydrofolate 22 (75.8\%) restored one spontaneous menstrual cycle during treatment time period and $20(70 \%)$ maintained the normal ovulatory activity 
during the follow up period. 7 patients did not respond to the therapy and no menstrual cycle observed during treatment time period. Vaginal/trans-abdominal USG and serum estradiol level of 22 patients done on 3rd day of menstrual cycle out of which 4 patients dropped due to cyst in ovary and serum estradiol level $\geq 50$. Ovulation induction done in 18 patients with clomiphene citrate at the dose of 50 further ovulated during treatment out of which 10 conceive, as compared with only 9 women out of the 25 women (36 percent) in the placebo group ovulate $(\mathrm{P}<0.001)$ out of which 4 conceived. The mean peak serum progesterone concentration in the 29 women in the treatment group who ovulated was $12.4 \pm 1.7 \mathrm{ng}$ per milliliter (39.4 $\pm 5.4 \mathrm{nmol}$ per liter).

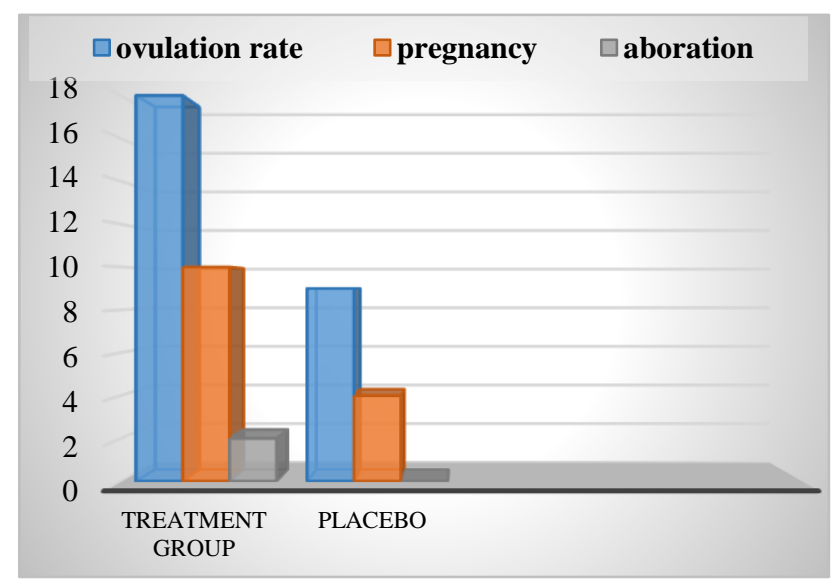

Figure 5: Treatment outcome in two groups.

\section{DISCUSSION}

PCOS is one of the most common endocrine disorders, it's the most common cause of female infertility and characterized by a combination of hyperandrogenism, chronic anovulation and irregular menstrual cycles. ${ }^{19,20}$ In about $50 \%$ of patients with PCOS, insulin receptor phosphorylation is impaired. Several trials showed that insulin sensitizer agents, such as metformin and Myoinositol, are the first-line treatment to restore normal menstrual cycles in women suffering from PCOS. ${ }^{20,21}$ Insulin resistance is main causative factor responsible for clinical features in PCOS. Failure of the target cells to respond to normal or ordinary levels of insulin is regarded as insulin resistance irrespective of the BMI. Hyperinsulinemia due to insulin resistance occurs in approximately $80 \%$ of obese PCOS women and $30-40 \%$ of lean PCOS women. ${ }^{22}$ However recent studies suggest that some abnormal action of insulin might be dependent upon inositol phosphoglycan (IPG) mediators of insulin action and suggest that a deficiency in inositol can lead to insulin resistance.

Actually no data exist on action and effects of Myoinositol, a precursor of DCI, on anovulatory women of reproductive age or on spontaneous ovulation in stimulated cycles. Myo-inositol is an important constituent of follicular microenvironment, playing a determinant role in both nuclear and cytoplasmic oocyte development. In fact, in IVF techniques supplementation by myo-inositol is positively related to meiotic progression of mouse germinal vesicle oocytes, enhancing intracellular $\mathrm{Ca} 2 \mathrm{p}$ oscillation. $^{23}$ Follicular fluid makes up the actual environment of the mature oocyte before fertilization and may influence IVF outcome parameters such as fertilization, embryo cleavage and pregnancy rates. ${ }^{24}$

In the present study, there was a significant decrease in the ovarian volumes, total antral follicle count, and serum AMH, SHBG, DHEA, total testosterone, and estradiol levels after treatment with myo-inositol and 1-5 methyltetrahydrofolate. Patients in the study group showed significantly more relevant reduction in DHEA levels $(\mathrm{p}=0.0003)$, AMH levels $(\mathrm{p}=0.0048)$, SHBG levels $(0.0100)$, estradiol levels $(\mathrm{p}=0.0079)$ and ovarian volume ( $\mathrm{p}=0.0001$ ) than the placebo group. There was significant decrease in total antral follicle count in treatment group. Based on our data, authors believe that myo-inositol with 1-5, methyltetrahydrofolate is more effective, safe and with better outcome therapy for PCOS associated infertility. Myo-inositol leads to reduction of testosterone is a key outcome in the management of PCOS women, because of the typical symptoms related to the hyperandrogenic status, affecting the PCOS pathway. These results could be due to the insulin sensitizing action of myo-inositol and the sequent down regulation of the androgens production at ovarian level.

Myo-inositol with L-5 Methyltetrahydrofolate led to improvement in biochemical profile over the period of 12 weeks. Myo-inositol with L-5 Methyltetrahydrofolate may be considered effective in treatment of clomiphene citrate resistance PCOS with better oocyte quality and pregnancy rate. Though the sample size and study duration was small in this study, further research with larger groups and longer study periods is required to support these findings.

\section{CONCLUSION}

Treatment of PCOS with myo-inositol $1200 \mathrm{mg}$ and L-5, Methyltetrahydrofolate $800 \mathrm{mcg}$ compared with that of placebo group after 12 weeks of treatment in patient with clomiphene citrate resistance PCOS women experienced an improvement in their menstrual cyclicity. Very less number of treated patient showed resistance to the treatment with no significant changes in ovary pathology, volume and residual cysts.

There is significant statically changes in anthropometric, biochemical and hormonal parameters in treated group comparison to placebo group. More no of studied and treated case get back to normal ovulatory cycles and maintained the ovulation cyclicity. Significant dec in serum estradiol level seen on day of HCG administration in ovulation induction.

In conclusion, these observations suggest that Myo-inositol may prove useful in the treatment of PCOS patients 
undergoing ovulation induction, both for its insulinlowering activity and its intracellular role in oocyte maturation.

\section{Funding: No funding sources}

Conflict of interest: None declared

Ethical approval: The study was approved by the Institutional Ethics Committee

\section{REFERENCES}

1. The Rotterdam ESHRE/ASRM-sponsored PCOS consensus workshop group. Revised 2003 consensus on diagnostic criteria and long-term health risks related to polycystic ovary syndrome (PCOS). Hum Reprod. 2004;19:41-7.

2. Zawadski JK, Dunaif A. Diagnostic criteria for polycystic ovary syndrome: towards a rational approach. In: Dunaif A, Givens JR, Haseltine F, editors. Polycystic ovary syndrome. Boston: Blackwell Scientific; 1992:377-384.

3. Azziz R, Carmina E, Dewailly D, Diamanti-Kandarakis E, Escobar-Morreale HF, Futterweit W, et al. Criteria for defining polycystic ovary syndrome as a predominantly hyperandrogenic syndrome: an androgen excess society guideline. The Journal of Clinical Endocrinology \& Metabolism. 2006 Nov 1;91(11):4237-45.

4. Hourvitz A, Machtinger R, Maman E, Baum M, Dor J, Levron J. Assisted reproduction in women over 40 years of age: how old is too old? Reprod Biomed Online. 2009;19:599-603.

5. Wiener-Megnanzi Z, Vardi L, Lissak A, Shnizer S, Reznick AZ, Ishai D, et al. Oxidative stress indices in follicular fluid as measured by the thermochemiluminescence assay correlate with outcome parameters in in vitro fertilization. Fertil Steril. 2004;82(3):1171-6.

6. Steegers-Theunissen RP, Boers GH, Blom HJ, Trijbels FJ, Eskes TK. Hyperhomocysteinemia and recurrent spontaneous abortion or abruptio placentae. Lancet 1992;339(8801):1122-3.

7. Wouters MG, Boers GH, Blom HJ, Trijbels FJ, Thomas CM, Borm GF, et al. Hyperhomocysteinemia: a risk factor in women with unexplained recurrent early pregnancy loss. Fertil Steril. 1993;60:820-5.

8. Hague WM. Homocysteine and pregnancy. Best Pract Res Clin Obstet Gynaecol. 2003;17:459-69.

9. Refsum H, Smith AD, Ueland PM, Nexo E, Clarke R, Mcpartlin J, et al. Facts and recommendations about total homocysteine determinations: an expert opinion. Clin Chem. 2004;50:3-32.

10. Boxmeer JC, Brouns RM, Lindemans J, Steegers EA, Martini E, Macklon NS, et al. Preconception folic acid treatment affects the microenvironment of the maturing oocyte in humans. Fertil Steril. 2008;89:1766-70.

11. Chiu TT, Rogers MS, Law Elk, Briton- CM, Cheung LP, Haines CJ. Follicular fluid and serum concentrations of myo-inositol in patients undergoing IVF: relationship with oocyte quality. Hum Reprod. 2002;17:1591-6.
12. Chiu TT, Rogers MS, Briton-Jones C, Haines C. Effect of myo-inositol on the in-vitro maturation and subsequent development of mouse oocytes. Hum Reprod. 2003;18:408-16.

13. Chiu TT, Tam PP. A correlation of the outcome of clinical in vitro fertilization with the inositol content and embryotrophic properties of human serum. Journal of assisted reproduction and genetics. 1992 Dec 1;9(6):52430.

14. Papaleo E, Unfer V, Baillargeon JP, Fusi F, Occhi F, DE Santis L. Myo-inositol may improve oocyte quality in intracytoplasmic sperm injection cycles. A prospective, controlled, randomized trial. Fertil Steril. 2009;91:17504.

15. Fahy MM, Kane MT. Incorporation of $[3 \mathrm{H}]$ inositol into phosphoinositides and inositol phosphates by rabbit blastocysts. Mol Reprod Dev. 1993;34:391-5.

16. Holm P, Booth PJ, Schmidt MH, Greve T, Callesen H. High bovine blastocyst development in a static in vitro production system using SOFaa medium supplemented with sodium citrate and myo-inositol with or without serum-proteins. Theriogenology. 1999;52:683-700.

17. Berridge MJ, Irvine RF. Inositol phosphates and cell signalling. Nature. 1989 Sep;341(6239):197.

18. Sirmans SM, Pate KA. Epidemiology, diagnosis and management of polycystic ovary syndrome. Clinical Epidemiology. 2014;6:1-13.

19. Unfer V, Nestler JE, Kamenov ZA, Prapas N, Facchinetti F. Effects of Inositol(s) in women with PCOS: a systematic review of randomized controlled trials. International journal of Endocrinology. 2016:1849162.

20. Nehra J, Kaushal J, Singhal SR, Ghalaut VS. A comparative study of efficacy and safety of myo-inositol versus metformin in polycystic ovarian syndrome in women. World Journal of Pharmacy and Pharmaceutical Sciences. 2016;5(5):884-96.

21. Hu L, Shen H, Wu QF, Tian L, Hu MH. Treatment of polycystic ovarian syndrome with insulin sensitizer. Clinical Experimental Obstetrics and Gynaecology. 2014;41:288-92.

22. Legro RS, Castracane VD, Kauffman RP. Detecting insulin resistance in polycystic ovary syndrome: purposes and pitfalls. Obstetrical and Gynecological Survey. 2004;59:141-54.

23. Agarwal A, Saleh RA, Bedaiway MA. Role of reactive oxygen species in the pathophysiology of human reproduction. Fertil Steril. 2003;79:829-43.

24. Pesty A, Avazeri N, Lefevre B. Nuclear calcium release by InsP3-receptor channels plays a role in meiosis reinitiating in the mouse oocyte. Cell Calcium. 1998;24:239-51.

Cite this article as: Bhardwaj A, Shukla A, Singh S, Agarwal R. Pre-treatment effect of myo-inositol and $1-5$, methyltetrahydrofolate in ovulation induction oocyte quality and pregnancy outcome in clomiphene resistance polycystic ovarian disease. Int J Basic Clin Pharmacol 2018;7:532-6. 